\title{
Níveis nutricionais de treonina digestível para poedeiras leves no segundo ciclo de produção
}

\author{
Marlene Schmidt ${ }^{1}$, Paulo Cezar Gomes ${ }^{2}$, Horacio Santiago Rostagno ${ }^{2}$, Luiz Fernando \\ Teixeira Albino ${ }^{2}$, Christiane Garcia Vilela Nunes ${ }^{3}$, Ricardo Vianna Nunes ${ }^{3}$
}

\footnotetext{
1 Doutoranda em Zootecnia, UFV - 36571-000 - Viçosa, MG.

2 Departamento de Zootecnia, UFV - 36571-000 - Viçosa, MG.

${ }^{3}$ Curso de Zootecnia, UNIOESTE - 85960-000 - Marechal Candido Rondon, PR.
}

RESUMO - Com o objetivo de determinar a exigência nutricional de treonina digestível para poedeiras comerciais leves de segundo ciclo de produção (79 a 95 semanas de idade), foi conduzido um experimento com 180 poedeiras Lohmann LSL, distribuídas em cinco dietas $(0,380 ; 0,413 ; 0,446 ; 0,479$; e 0,512\% de treonina digestível), seis repetições e seis aves por unidade experimental. Os níveis de treonina na ração tiveram efeito quadrático sobre o consumo de ração, a conversão alimentar por massa e por dúzia de ovos, a taxa de postura, o peso e a massa de ovos. Não foi observado efeito significativo dos níveis de treonina na ração sobre o ganho de peso, a unidade Haugh, o índice de gema e de albúmen e a porcentagem de gema e de albúmem, com exceção da porcentagem de casca, que sofreu efeito quadrático. Mediante análise estatística e interpretação biológica e tomando-se a conversão alimentar por dúzia de ovos como parâmetro decisório, a exigência de treonina digestível no período de 79 a 95 semanas de idade é de $0,469 \%$, que corresponde a um consumo de treonina de $459 \mathrm{mg} / \mathrm{ave} / \mathrm{dia}$.

Palavras-chave: aminoácido, produção de ovos, qualidade de ovos

\section{Nutritional levels of digestible threonine for white-egg laying hens in the second cycle of production}

\begin{abstract}
In order to determine nutritional requirement of digestible threonine for white-egg laying hens in the second production cycle (from 79 to 95 weeks of age), it was carried out an experiment with 180 commercial Lohmann LSL laying hens, distributed in five diets $(0.380 ; 0.413 ; 0.446 ; 0.479$ and $0.512 \%$ digestible threonine), six replicates and six birds per experiment unit. Levels of threonine in the ration quadratically affected feed intake, feed conversion per mass and per dozen of eggs, laying rate, weight and mass of eggs. It was not observed significant effect of the levels of threonine in the ration on weight gain, Haugh unity, index of yolk and albumen and percentage of yolk and albumen, except for shell percentage, which was quadratically affected. Through statistic analyzes and biological interpretation and using feed conversion per dozen of eggs as a decision parameter, the requirement of digestible threonine in the period from 79 to 95 weeks of age is $0.469 \%$, corresponding to a threonine consumption of $459 \mathrm{mg} / \mathrm{bird} / \mathrm{day}$.
\end{abstract}

Key Words: amino acids, egg production, egg quality

\section{Introdução}

Os aminoácidos participam de uma complexa variedade de reações metabólicas, sendo que o excesso ou deficiência na sua ingestão não resulta em alterações graves no organismo animal, podendo entretanto alterar o padrão ótimo de utilização dos aminoácidos levando o animal a um menor desempenho. Tem-se observado que a ingestão desproporcional de aminoácidos em quantidades ou padrões daqueles requeridos para a máxima utilização pelos tecidos corporais, o que resulta em animais de desempenho comprometido.
A formulação de rações, com base em aminoácidos totais, deficiências e/ou excessos pode ocorrer, em função da variabilidade dos dados relativos a digestibilidade dos aminoácidos. Como medida para contornar este problema, surge o conceito de proteína ideal, que implica no conhecimento da digestibilidade verdadeira dos aminoácidos, permitindo formulações sem excessos e deficiências. Formular uma dieta com base no conceito de proteína ideal significa suprir o mínimo e de forma equilibrada, necessária para a obtenção do ótimo desempenho dos animais. Como consequência, a retenção de proteína (ganho em relação ao consumo) é máxima e a excreção de nitrogênio é mínima 
(Leclercq, 1998). De acordo Andrade et al. (2003) a formulação de rações com base nos níveis de aminoácidos é um conceito muito utilizado na nutrição avícola, principalmente para a redução do teor de proteína bruta nas rações, porém pode ser realizado desde que se atendam as exigências dos principais aminoácidos.

Nesse sentido, a treonina digestível deve ser considerada nas rações de poedeiras, pois o seu excesso ou deficiência pode comprometer o desempenho das aves e o custo de produção.

As evidências experimentais apoiando as recomendações de treonina digestível são esparsas e conflitantes. Para poedeiras de segundo ciclo de produção são poucos os trabalhos. Ishibashi et al. (1998) determinaram a exigência de treonina para poedeiras comerciais com base nos parâmetros de desempenho e concentrações plasmáticas de treonina. Concluíram que a exigência de treonina expressa em mg/ave/dia, determinada com base na treonina plasmática apresentou valores concordantes com aquela obtida para o desempenho e determinaram a exigência diária de $455 \mathrm{mg} /$ ave/dia para a máxima produção de massa de ovos.

Valério et al. (2000) sugerem 0,423\% de treonina digestível para poedeiras leves. Rostagno et al. (2000) e (2005) preconizam 0,438\% e 0,525\% de treonina digestível, respectivamente. Teixeira et al. (2005) recomendam 0,530\% ou $625 \mathrm{mg} / \mathrm{ave} /$ dia de treonina digestível.

O objetivo neste trabalho foi estabelecer a exigência de treonina digestível para poedeiras comerciais leves no segundo ciclo de produção.

\section{Material e Métodos}

O experimento foi conduzido no no Setor de Avicultura da Universidade Federal de Viçosa, no período de março a agosto de 2004. Foram utilizadas 180 poedeiras leves da linhagem Lohmann LSL, distribuídas em cinco rações, seis repetições e seis aves por unidade experimental em um delineamento inteiramente casualizado.

Nas fases de cria, recria e produção, as aves foram manejadas conforme descrito nos manuais das linhagens, entretanto seguindo-se as recomendações de Rostagno et al. (2000) para a elaboração das dietas. Na fase de produção, as aves foram alojadas aos pares, em gaiolas de $25 \times 40 \times 45 \mathrm{~cm}$, num galpão de postura de $60 \times 9 \mathrm{~m}$, fechado com tela nas laterais e coberto com telha de barro.

As aves foram submetidas à muda-forçada às 72 semanas de idade, quando a postura caiu para $75 \%$, utilizando-se a metodologia de Cotta (2002).

Depois de completado o período de jejum, as aves receberam ração para frangas, seguindo as recomendações de Rostagno et al. (2000), e, somente quando atingiram 50\% de postura, o que correspondeu a uma idade de 79 semanas, passaram a receber as dietas experimentais.

Para determinação da exigência de treonina digestível, foram formuladas rações isoproteicas, variando em 5 níveis de suplementação de treonina digestível obedecendo às relações de treonina:lisina de 58; 63; 68; 73 e 78\% com a lisina fixada em $0,653 \%$. Os níveis foram obtidos a partir de uma dieta basal (Tabela 1) deficiente em treonina $(0,380 \%)$, suplementada com 0,$00 ; 0,036 ; 0,065 ; 0,108$; e 0,144\% de L-treonina (98\%), de forma a proporcionar 0,380; 0,413; 0,446; 0,479; e 0,512\% de treonina digestível nas rações. Para cada nível de suplementação, foi mantida a relação dos aminoácidos essenciais em relação à lisina. As suplementações com L-treonina (98\%) foram feitas em substituição ao aminoácido não essencial L-glutâmico. Os demais nutrientes contidos nas rações, exceto proteína bruta, atenderam as recomendações preconizadas por Rostagno et al. (2000).

A partir da 79a semana de idade, as poedeiras foram submetidas as rações experimentais, iniciando-se o período experimental, que teve a duração de 16 semanas, subdivididos em 4 períodos de 28 dias cada. As rações foram fornecidas, diariamente, em dois horários, às 7 e às $17 \mathrm{~h}$, garantindo às aves consumo de alimento e água, à vontade, durante todo o período experimental.

O programa de luz utilizado foi o mesmo adotado pelo Setor de Avicultura do Departamento de Zootecnia da Universidade Federal de Viçosa, considerando a época de nascimento das aves e o tipo da instalação (16 horas/dia de luz).

Os parâmetros avaliados a cada período de 28 dias foram: consumo de ração, consumo de treonina, conversão alimentar/dúzia de ovos, conversão alimentar/massa de ovos, taxa de postura, peso de ovos, massa de ovos, porcentagem dos componentes dos ovos (casca, albúmen e gema), qualidade interna dos ovos (unidade Haugh, índice de gema e índice de albúmen). O ganho de peso foi avaliado somente no final do período experimental.

Para determinação da porcentagem dos componentes dos ovos e da qualidade interna, foram coletados 4 ovos/ unidade experimental nos três últimos dias de cada período, dois para determinação da porcentagem de casca, albúmen e gema e dois para determinação da unidade Haugh, índice de gema e de albúmen.

Para a obtenção da porcentagem dos componentes dos ovos, obteve-se primeiramente o peso total do ovo e em seguida procedeu-se à quebra do mesmo para a pesagem da gema e da casca. As cascas foram pesadas após de secas em temperatura ambiente por 4 dias. O peso do albúmen foi 
Tabela 1 - Composição percentual e valor nutricional das dietas

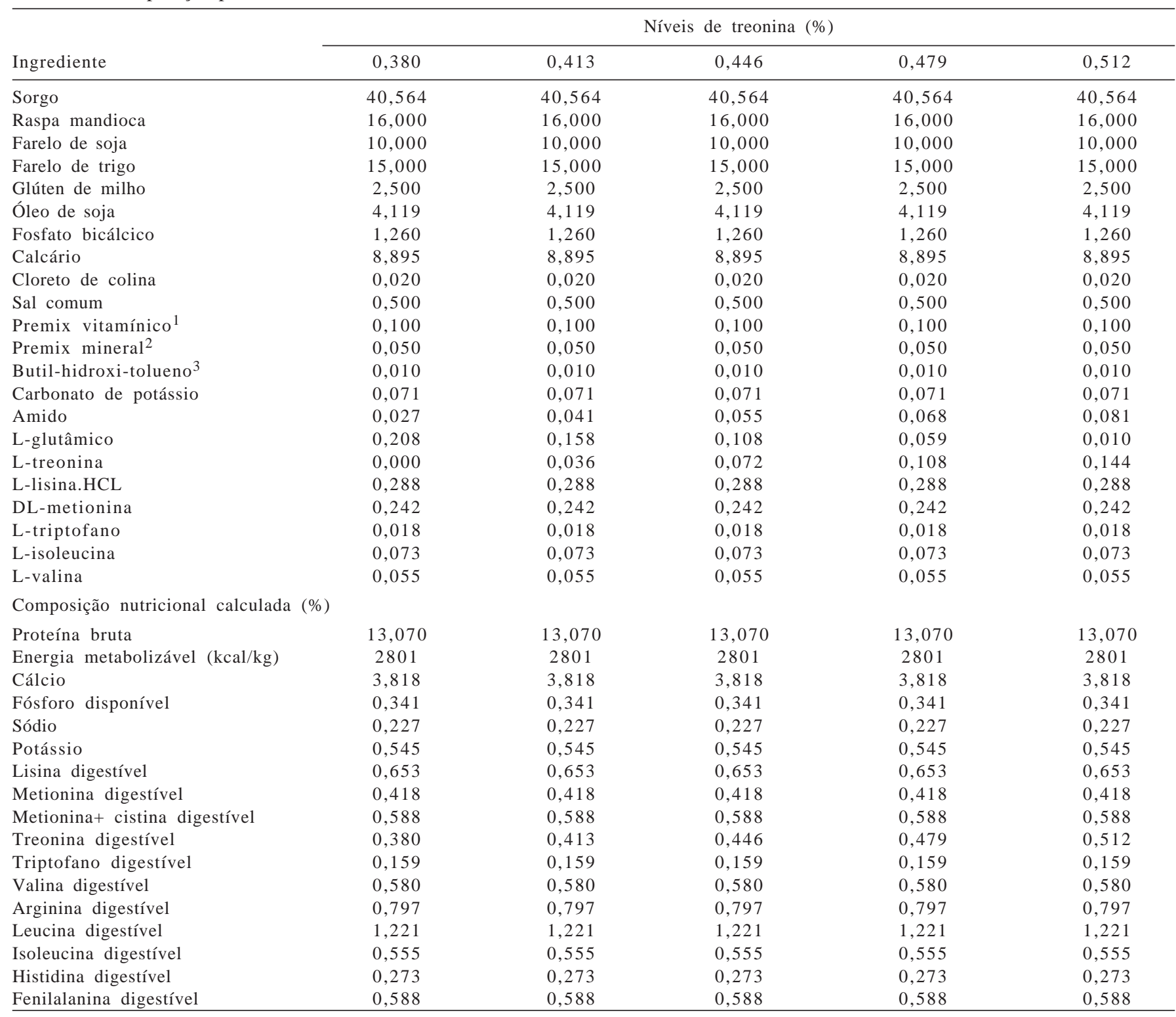

${ }^{1}$ Vitamina matrizes (composição/kg): vit. A - 12.000.000 U.I.; vit $\mathrm{D}_{3}$ - 3.600.000 U.I.; vit. E - 3.500 U.I.; vit. B $\mathrm{B}_{1}$ - 2.500 mg; vit. B $\mathrm{B}_{2}$ - 8.000 mg; vit. B 6 - 3.000 mg; ácido pantotênico - 12.000 mg; biotina - 200 mg; vit. K - 3.000 mg; ácido fólico - 3.500 mg; ácido nicotínico - 40.000 mg; vit. B 12 - 20.000 mcg; Se - 130 mg; veículo q.s.p. - $1.000 \mathrm{~g}$.

${ }^{2}$ Mineral aves (composição/kg): Mn - 160 g; Fe - 100 g; Zn - 100 g; Cu - 20 g; Co - 2 g; I - 2 g; excipiente q.s.p. - 1000 g.

3 Butil-hidroxi-tolueno (antioxidante).

obtido pela diferença entre o peso total do ovo menos o peso da casca e da gema.

Para a determinação da unidade Haugh, procedeu-se a quebra dos ovos para a medição da altura de albúmen por meio de micrômetro tipo AMES S-6428 e em seguida determinou-se a unidade Haugh utilizando a fórmula desenvolvida por Haugh (1937). Para a determinação dos índices de albúmem e de gema, foram medidos os diâmetros de albúmem e de gema, com paquímetro e a altura de albúmen e de gema por meio do micrômetro tipo AMES S-6428.

O consumo de ração foi determinado ao final de cada período, subtraindo-se a quantidade de ração fornecida pela sobra de ração nos comedouros. Com base neste consumo e na porcentagem de treonina em cada tratamento, determinou-se o consumo de treonina, em mg/ave/dia. A conversão alimentar foi calculada pela divisão do consumo de ração pela produção em dúzias de ovos (kg/dúzia) e pela massa de ovos (g/g), em cada um dos quatro períodos.

A coleta de ovos foi realizada diariamente e o cálculo da taxa de postura baseou-se no número de ovos/ave/dia. Os ovos foram pesados nos quatro últimos dias de cada período experimental para a determinação do peso e da massa de ovos, esta última obtida através do produto do número de ovos produzidos em cada período pelo peso médio dos ovos. 
As análises estatísticas das variáveis avaliadas foram realizadas de acordo com o programa SAEG - Sistema para Análises Estatísticas e Genéticas (UFV, 1999) mediante o uso dos modelos de regressão (linear e quadrático). Para estimar a exigência de treonina digestível, foi utilizado o modelo que melhor se ajustou aos dados obtidos às variáveis de desempenho.

\section{Resultados e Discussão}

Observou-se efeito dos níveis de treonina sobre o consumo de treonina e de ração, sobre a conversão alimentar por massa de ovos e por dúzia de ovos (Tabela 2). O consumo de treonina aumentou linearmente $(\mathrm{P}<0,01)$, comprovando deste modo que os níveis utilizados não influenciaram o consumo de ração. Faria et al. (2002) também observaram aumento linear significativo no consumo de treonina à medida que se aumentavam os níveis de treonina na ração, tanto para o período de 31 a 38 semanas de idade como para o período de 45 a 52 semanas de idade.

Diferente do observado nesta pesquisa, Sá et al. (2007), trabalhando com níveis de treonina digestível variando de 0,410 a $0,550 \%$ em rações para poedeiras de 34 a 50 semanas de idade, não observaram influência $(\mathrm{P}>0,05)$ dos níveis de treonina sobre o consumo de ração. Valério et al. (2000), em experimento com 0,510 a $0,635 \%$ de treonina, não observaram influência dos níveis de treonina sobre a conversão alimentar, também diferindo dos resultados observados neste trabalho.

As exigências de treonina estimadas para consumo de ração, conversão alimentar por dúzia e por massa de ovos foram de 0,452; 0,469 e 0,460\%, respectivamente, o que equivale a consumo de 441; 459 e $449 \mathrm{mg} /$ ave/dia de treonina, respectivamente. Valério et al. (2000) observaram efeito quadrático $(\mathrm{P}<0,05)$ dos níveis de treonina para o consumo de ração de poedeiras leves de 21 a 36 semanas de idade e estimaram exigência de treonina em $0,574 \%$, equivalente a um consumo de 95,65 g de ração/ave/dia.

O valor de exigência estimado neste experimento para melhor conversão alimentar por dúzia de ovos, ficou distante do valor estimado por Sá et al. (2007), que observaram efeito quadrático $(\mathrm{P}<0,01)$ dos níveis de treonina sobre a conversão alimentar por dúzia de ovos em aves de 34 a 50 semanas de idade e determinaram exigência 0,510\% de treonina, correspondente a consumo diário de $583 \mathrm{mg} /$ ave/dia de treonina digestível. Já para o consumo de ração, esses autores não observaram efeito dos níveis de treonina na ração.

Por outro lado, a exigência de treonina estimada neste experimento para melhor conversão alimentar por dúzia de ovos foi próxima à encontrada por Ishibashi et al. (1998), que, estudando os efeitos da inclusão de treonina (0,31 a $0,61 \%$ - experimento 1 e 0,31 a $0,51 \%$ - experimento 2 ) sobre a conversão alimentar por dúzia de ovos em poedeiras de 29 a 30 semanas de idade, observaram exigências de 0,428 e $0,404 \%$ ou 456 e $467 \mathrm{mg}$ de treonina/ave/dia no primeiro e segundo experimento, respectivamente.

Os valores de taxa de postura, peso de ovos e massa de ovos sofreram influência quadrática $(\mathrm{P}<0,01)$ dos níveis de treonina na ração (Tabela 2). Esses resultados comprovam que, a partir de determinado nível de treonina na ração, os resultados dessas variáveis pioravam. A exigência estimada de treonina para essas variáveis foram de 0,$465 ; 0,445$ e $0,459 \%$ de treonina digestível, o que corresponde a um consumo de 455, 433 e $448 \mathrm{mg}$ de treonina/ave/dia, respectivamente.

Faria et al. (2002) observaram para as características de produção e massa de ovos significativo aumento linear à

Tabela 2 - Níveis de treonina sobre o consumo de ração e treonina, conversão alimentar por dúzia e massa de ovos, taxa postura, peso e massa de ovos

\begin{tabular}{|c|c|c|c|c|c|c|}
\hline & \multicolumn{5}{|c|}{ Nível de treonina (\%) } & \multirow[t]{2}{*}{ CV $(\%)$} \\
\hline & 0,380 & 0,413 & 0,446 & 0,479 & 0,512 & \\
\hline Consumo ração (g/ave/dia) ${ }^{1,3^{* *}}$ & 106,64 & 107,25 & 107,82 & 108,02 & 106,82 & 0,91 \\
\hline Conversão alimentar por dúzia de ovos (kg/dúzia) ${ }^{1,4 *}$ & 2,00 & 1,93 & 1,86 & 1,85 & 1,89 & 3,98 \\
\hline Conversão alimentar por massa de ovos $(\mathrm{g} / \mathrm{g})^{1,5^{* *}}$ & 2,46 & 2,36 & 2,28 & 2,24 & 2,37 & 4,48 \\
\hline Taxa postura $(\%)^{1,6 *}$ & 64,96 & 67,00 & 69,69 & 70,55 & 67,82 & 4,00 \\
\hline
\end{tabular}

1 Efeito quadrático.

2 Efeito linear; ** $(\mathrm{P}<0,01)$ e * $(\mathrm{P}<0,05)$

$3 \hat{Y}=54,3184+236,773 x-261,612 x^{2}\left(R^{2}=0,87\right)$

$4 \hat{Y}=6,01077-17,6954 x+18,8465 x^{2}\left(R^{2}=0,99\right)$.

$5 \hat{Y}=9,17045-29,9934 x+32,5729 x^{2}\left(R^{2}=0,92\right)$.

$6 \hat{Y}=-91,1910+693,071 x-745,480 x^{2}\left(R^{2}=0,91\right)$

$7 \hat{Y}=0,173896+306,454 x-344,421 x^{2}\left(R^{2}=0,85\right)$.

$8 \hat{Y}=-106,525+672,518 x-733,244 x^{2}\left(R^{2}=0,89\right)$. 
medida que aumentaram os níveis de treonina na dieta de poedeiras leves. De acordo com a regressão broken-line, a exigência diária de treonina foi de 439,0 e 462,1 mg/ave/dia (experimento 1 - 31 a 38 semanas de idade) e de 393,9 e $447,1 \mathrm{mg} /$ ave/dia (experimento 2 - 45 a 52 semanas de idade) para produção e massa de ovos, respectivamente.

Em poedeiras de 21 a 36 semanas de idade, Valério et al. (2000) não observaram efeito dos níveis de treonina na ração sobre a produção de ovos. Por outro lado, notaram efeito quadrático dos níveis de treonina sobre o peso e a massa de ovos. A exigência de treonina para peso e massa de ovos foi de $0,573 \%$ para peso mínimo de ovo de 55,18 g e de $0,570 \%$ de treonina e para massa mínima de ovos de 43,81 g/ave/dia.

Sá et al. (2007) também observaram efeito quadrático $(\mathrm{P}<0,05)$ dos níveis de treonina para produção e massa de ovos. No entanto, o peso médio dos ovos não foi influenciado ( $\mathrm{P}>0,01)$ pelos níveis de treonina nas rações. A exigência de treonina estimada por esses autores para produção de ovos foi de $0,499 \%$, correspondente a um consumo médio diário de treonina de $570 \mathrm{mg} /$ ave. Para massa de ovos, o valor encontrado foi $0,501 \%$ de treonina, equivalente a um consumo médio diário de $573 \mathrm{mg} / \mathrm{ave}$. Como pode ser observado, o valor de exigência para melhor produção e massa de ovos relatados por Sá et al. (2007) foi superior ao encontrado neste trabalho.
Não foi observado efeito significativo $(\mathrm{P}>0,05)$ dos níveis de treonina na ração para unidade Haugh, índice de gema e de albúmen (Tabela 3), o que indica que não houve deficiência de treonina na ração com $0,380 \%$ para os parâmetros avaliados. Esses resultados concordam, em parte, com os obtidos por Valério et al. (2000), que também observaram que os níveis de treonina na ração não influenciaram $(\mathrm{P}>0,01)$ a qualidade interna dos ovos de poedeiras leves de 21 a 36 semanas de idade. Semelhantes resultados foram reportados por Sá et al. (2007), no entanto, esses autores observaram efeito quadrático $(\mathrm{P}<0,01)$ sobre a unidade Haugh de ovos de poedeiras de 34 a 50 semanas de idade.

Não foi observado efeito significativo $(\mathrm{P}>0,05)$ dos níveis de treonina na ração para as características de qualidade de ovos (Tabela 3), com exceção da porcentagem de casca, que sofreu efeito quadrático $(\mathrm{P}<0,01)$. O menor nível de treonina $(0,380 \%)$ utilizado na ração não comprometeu as variáveis estudadas (Tabela 3), exceto a porcentagem de casca, que foi maior.

A exigência de treonina estimada para melhor porcentagem de casca foi de $0,488 \%$, que equivale a um consumo de $480 \mathrm{mg}$ de treonina/ave/dia. O ganho de peso não foi influenciado $(\mathrm{P}>0,05)$ pelos níveis de treonina na ração (Tabela 4).

Os valores de exigência de treonina digestível, considerando as principais variáveis estudadas (Tabela 5),

Tabela 3 - Unidade Haugh, índices de gema e de albúmen e porcentagem de casca, de albúmem e de gema em poedeiras no segundo ciclo de produção recebendo diferentes níveis de treonina na ração

\begin{tabular}{|c|c|c|c|c|c|c|}
\hline & \multicolumn{5}{|c|}{ Nível de treonina (\%) } & \multirow[t]{2}{*}{ CV (\%) } \\
\hline & 0,380 & 0,413 & 0,446 & 0,479 & 0,512 & \\
\hline Unidade Haugh & 88,75 & 90,42 & 90,56 & 90,11 & 90,74 & 2,44 \\
\hline Índice de gema & 0,466 & 0,481 & 0,487 & 0,480 & 0,483 & 5,67 \\
\hline Índice de albúmen & 0,114 & 0,114 & 0,116 & 0,115 & 0,115 & 6,18 \\
\hline$\%$ de casca $^{1,2}$ & 10,52 & 9,85 & 9,97 & 9,70 & 9,71 & 2,15 \\
\hline \% de albúmen & 63,02 & 63,77 & 63,79 & 63,74 & 63,63 & 1,09 \\
\hline$\%$ de gema & 26,45 & 26,38 & 26,24 & 26,58 & 26,66 & 2,38 \\
\hline
\end{tabular}

${ }^{1}$ Efeito quadrático $(\mathrm{P}<0,01)$.

$2 \hat{Y}=24,9388-62,4508 x+63,9867 x^{2}\left(R^{2}=0,84\right)$.

Tabela 4 - Ganho de peso de poedeiras leves no período de 79 a 95 semanas de idade recebendo diferentes níveis de treonina na ração

\begin{tabular}{lccc}
\hline $\begin{array}{l}\text { Treonina } \\
(\%)\end{array}$ & $\begin{array}{c}\text { Peso inicial } \\
\text { (g/ave) }\end{array}$ & $\begin{array}{c}\text { Peso final } \\
\text { (g/ave) }\end{array}$ & $\begin{array}{c}\text { Ganho peso } \\
\text { (g/ave) }\end{array}$ \\
\hline 0,380 & 1537 & 1477 & -60 \\
0,413 & 1539 & 1461 & -78 \\
0,446 & 1539 & 1468 & -71 \\
0,479 & 1540 & 1488 & -52 \\
0,512 & 1537 & 1446 & -91 \\
CV $(\%)$ & 0,83 & 3,20 & $-22,19$ \\
\hline
\end{tabular}

Tabela 5 - Exigências nutricionais de treonina digestível e relação treonina/lisina no período de 79 a 95 semanas de idade

\begin{tabular}{lccc}
\hline Parâmetro & $\begin{array}{c}\text { Treonina } \\
(\%)\end{array}$ & $\begin{array}{c}\text { Treonina } \\
\text { (mg/dia) }\end{array}$ & $\mathrm{R}$ \\
\hline Taxa de postura (\%) & 0,465 & 455 & 71 \\
Massa de ovos (g/ave/dia) & 0,459 & 448 & 70 \\
Peso de ovos (g) & 0,445 & 433 & 68 \\
Conversão alimentar & 0,469 & 459 & 72 \\
(kg ração/dúzia de ovos) & & & 70 \\
Conversão alimentar & 0,460 & 449 & \\
(g ração/g massa de ovos) & & &
\end{tabular}


variaram de 0,445 a 0,469\%. Utilizando-se a conversão alimentar por dúzia de ovos, o maior valor de exigência em treonina foi de $0,469 \%$ de treonina digestível, que corresponde a consumo de $459 \mathrm{mg}$ de treonina/ave/dia, no período de 79 a 95 semanas de idade (Figura 1).

A exigência de treonina digestível de $0,469 \%$ para aves leves proporciona relação treonina/lisina de 0,72 . Relação inferior foi preconizada por Rostagno et al. (2000), que sugeriram relação de treonina/lisina de 0,62 para aves leves em fase de produção. Embora tenham aumentando o valor da relação treonina/lisina para 0,66, Rostagno et al. (2005) recomendaram relação inferior à determinada neste experimento.

De acordo com as respostas biológicas das aves aos níveis de treonina digestível estudados, Cupertino et al. (2010) sugeriram o valor de $0,446 \%$ de treonina digestível como exigência para poedeiras leves no período de 50 a 70 semanas de idade. Esse nível corresponde a consumo diário de $487 \mathrm{mg}$ de treonina/ave/dia. O valor de $0,446 \%$ de treonina digestível gera relação treonina/lisina de 68 , ficando um pouco abaixo da relação treonina/lisina encontrada neste trabalho (70).

Maior consumo de treonina digestível foi encontrado por Teixeira et al. (2005), que, em pesquisa com poedeiras de 44 a 53 semanas de idade, recomendaram $0,530 \%$ ou $625 \mathrm{mg} / \mathrm{ave} /$ dia de treonina digestível. Semelhantemente, Valério et al. (2000) também recomendaram maior consumo de treonina digestível: 0,515 mg/ave/dia $(0,423 \%$ de treonina digestível) para poedeiras leves de 21 a 36 semanas de idade. Ishibashi et al. (1998), considerando tanto os parâmetros de desempenho como os plasmáticos, determinaram exigência de treonina para poedeiras de

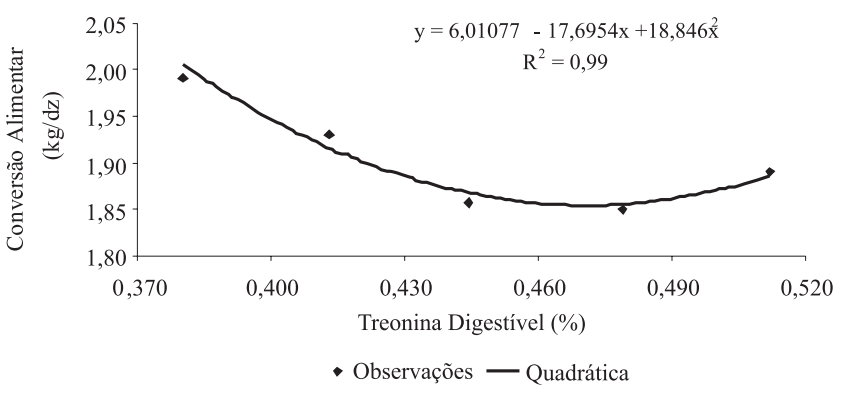

Figura 1 - Conversão alimentar de poedeiras no período de 79 a 95 semanas de idade recebendo diferentes níveis de treonina digestível na ração.
$455 \mathrm{mg} / \mathrm{ave} / \mathrm{dia}$, valor mais próximo ao deste trabalho, entretanto foi determinado com aves entre 29 e 39 semanas de idade.

\section{Conclusões}

A exigência de treonina digestível é de $0,469 \%$, que corresponde a um consumo de $459 \mathrm{mg} / \mathrm{ave} / \mathrm{dia}$, para poedeiras leves no período de 79 a 95 semanas de idade.

\section{Referências}

ANDRADE, L.; JARDIM FILHO, R.M.; STRINGHINI, J.H. et al. O uso de rações com diferentes níveis de proteínas suplementadas com aminoácidos na alimentação de poedeiras na fase inicial de produção. In: CONFERÊNCIA APINCO DE CIÊNCIA E TECNOLOGIA AVÍCOLAS - Trabalhos de Pesquisa. 2003, Campinas. Anais... Campinas, 2003. p.66.

COTTA, T. Galinha: produção de ovos. Viçosa, MG: Aprenda fácil, 2002. 280p.

CUPERTINO, E.S.; GOMES, P.C.; VARGAS JUNIOR, J.G. et al. Níveis nutricionais de treonina digestível para poedeiras comerciais durante o segundo ciclo de postura. Revista Brasileira de Zootecnia, v.39, n.9, p.1993-1998, 2010.

FARIA, D.E.; HARMS, R.H.; RUSSEL, G.B. et al. Threonine requirement of comercial laying hens fed a corn-soybean meal diet. Poultry Science, v.81, p.809-14, 2002.

HAUGH, R.R. The Haugh Unit for measuring egg quality. United State Egg and Poultry Magazine, v.4, p.552, 1937.

ISHIBASHI, T.; OGAWA, T.; ITO, S. et al. Threonine requirements of laying hens. Poultry Science, v.77, p.998-1002, 1998.

LECLERCQ, B. El concepto de proteína ideal y el uso de aminoácidos sintéticos: estudio comparativo entre pollos y cerdos. In: CURSO DE ESPECIALIZACIÓN FEDNA. Fundación Española para el desarrollo de la nutrición animal, 14., 1998, Firá de Barcelona. Anais... Firá de Barcelona, 1998. p.191-202.

ROSTAGNO, H.S.; ALBINO, L.F.T.; DONZELE, J.L. et al. Tabelas brasileiras para aves e suínos; composição de alimentos e exigências nutricionais. Viçosa, MG: UFV, Departamento de Zootecnia, 2000. 141p.

ROSTAGNO, H.S.; ALBINO, L.F.T.; DONZELE, J.L. et al. Tabelas brasileiras para aves e suínos: composição de alimentos e exigências nutricionais. 2.ed. Viçosa, MG: UFV, Departamento de Zootecnia, 2005. 186p.

SÁ, L.M.; GOMES, P.C.; CECON, P.R. et al. Exigência nutricional de treonina digestível para galinhas poedeiras no período de 34 a 50 semanas de idade. Revista Brasileira de Zootecnia, v.36, p.1846-1853, 2007.

TEIXEIRA, E.N.M.; VILAR DA SILVA, J.H.; SILVA, E.L. et al. Exigência de treonina digestível para poedeiras leves e semipesada. In: CONFERÊNCIA APINCO DE CIÊNCIA E TECNOLOGIA AVÍCOLAS - Trabalhos de Pesquisa. 2005, Santos. Anais... Santos, 2005. p.131.

UNIVERSIDADE FEDERAL DE VIÇOSA - UFV. Central de Processamento de Dados - UFV/CPD. SAEG - Sistema para análise estatística e genética. Versão 8.0 Viçosa, MG: UFV, 1997. 54p.

VALÉRIO, S.R.; SOARES, P.R.; ROSTAGNO, H.S. et al Exigência nutricional de treonina para poedeiras leves e semipesadas. Revista Brasileira de Zootecnia, v.29, n.2, p.518-524, 2000. 